\title{
Development of a Tomographic Myelin Scan
}

\author{
K. A. Frey, SB, ${ }^{*}$ D. M. Wieland, PhD, $†$ L. E. Brown, BS, $\uparrow$ \\ W. L. Rogers, PhD, $†$ and B. W. Agranoff, MD*
}

\begin{abstract}
The principle that myelin can be imaged noninvasively using the emission tomographic distribution of a lipophilic radioactive tracer was investigated. Properties of agents suitable for noninvasive myelin scanning are discussed with specific reference to blood-brain barrier permeability, metabolism, and tracer lipophilicity. The brain distributions of inert tracers are correlated with their partitioning between octanol and saline. A test probe, iodobenzene, was labeled with iodine 125 for preliminary invasive studies in the rabbit. The equilibrium brain distribution, determined either autoradiographically or by regional dissection, corresponded closely to that of myelin. ${ }^{123}$ Ilabeled iodobenzene, a gamma-emitting analog, was then administered to a monkey, and tomographic reconstruction revealed a pattern of brain uptake corresponding to white matter.
\end{abstract}

Frey KA, Wieland DM, Brown LE, Rogers WL, Agranoff BW: Development of a tomographic myelin scan. Ann Neurol 10:214-221, 1981

While a number of neurological disorders are primarily or entirely manifested in white matter, myelinated brain regions are relatively inaccessible to current clinical imaging techniques. Although transmission computed tomography has proven invaluable in the clinical neurosciences, its use in the selective imaging of myelin is limited by the minimal difference in intrinsic electron densities of white and gray matter. Furthermore, in some diseases of white matter there may be little or no alteration in tissue density, thus minimizing the diagnostic value of transmission tomography techniques. In order to overcome these problems, some property other than tissue density must serve as the basis for a myelin imaging technique. The recent developments of gamma [15] and positron [24] emission tomographic techniques facilitate the design of a suitable method, since they permit measurement of the regional distribution of administered radiotracers rather than of tissue electron density. A unique property of white as compared to gray matter is its high lipid content [1], and thus it may be anticipated that a labeled lipophilic agent could be employed as a radioactive myelin stain. The present paper reports the development of such a radiographic technique and demonstrates imaging of brain myelin based on the equilibrium distribution of a model lipophilic tracer, iodobenzene (IBZ).

\section{Materials and Methods}

Octanol was purchased from Aldrich Chemical Company (Milwaukee, WI). Fluorobenzene (FBZ) was obtained from Tridom Chemical, Inc. (Hauppauge, NY) and IBZ from Eastman Kodak Company (Rochester, NY). Polysorbate- 80 was supplied by ICN (Cleveland, OH). $\left[{ }^{14} \mathrm{C}\right]-$ Diphenylhydantoin and $\left[{ }^{3} \mathrm{H}\right]$ antipyrene were obtained from New England Nuclear Corporation (Boston, MA). $\left[{ }^{14} \mathrm{C}\right]$ Phenobarbital, $\left[{ }^{14} \mathrm{C}\right]$ iodoantipyrene, and ACS scintillation counting fluid were provided by Amersham Corporation (Arlington Heights, IL). Sodium iodide labeled with iodine 123 was obtained from Crocker Laboratories (Davis, CA) or with high-specific-activity iodine 125 from Union Carbide, Inc. (Tuxedo, NY).

New Zealand rabbits weighing 2 to $4 \mathrm{~kg}$ were obtained from Langshaw Farms (Augusta, MI) and a male cynomolgus monkey (Macaca fascicularis) from Charles River Primates (Port Washington, NY). All animals were housed in individual cages with free access to food and water.

PARTITION COEFFICIENTS. Octanol and phosphatebuffered saline $(\mathrm{pH} 7.4)$ were each presaturated with the other. For determination of the partitioning of antipyrene, iodoantipyrene, diphenylhydantoin, and phenobarbital, trace amounts of the ${ }^{3} \mathrm{H}$ - or ${ }^{14} \mathrm{C}$-radiolabeled substance were added to $6 \mathrm{ml}$ centrifuge tubes containing $2 \mathrm{ml}$ each of octanol and saline, then were vortexed and centrifuged at 2,500 rpm in an International Model K centrifuge for 30 minutes to separate phases. Duplicate aliquots $(50 \mu \mathrm{l})$ of
From the *Department of Biological Chemistry and the + Division of Nuclear Medicine, Department of Internal Medicine, University of Michigan Medical School, Ann Arbor, MI 48109.
Address reprint requests to Dr Agranoff, University of Michigan, Neuroscience Laboratory Bldg, 1103 E Huron, Ann Arbor, MI 48109.

Received Jan 12, 1981, and in revised form Mar 10. Accepted for publication Mar 14, 1981 
both phases were analyzed for radioactivity in $10 \mathrm{ml}$ of ACS using a Beckman LS 9000 liquid scintillation spectrometer. To ascertain the possible presence of contaminating impurities in the radioactive compounds, the octanol phases were repartitioned against fresh saline and the determination of radioactivity in each phase repeated.

The partition coefficients of unlabeled FBZ and IBZ were determined spectrophotometrically. FBZ (50 to 100 $\mu$ ) was pipetted into a screw-capped glass centrifuge tube containing $5 \mathrm{ml}$ each of octanol and saline. Following vortex mixing and centrifugation, the octanol phase was removed and a $3 \mathrm{ml}$ aliquot of the saline phase was reextracted with $3 \mathrm{ml}$ of fresh octanol. Absorbance of this second octanol phase and appropriate dilutions of the first octanol phase were determined at $261 \mathrm{~nm}$. Because of its high octanol/water ratio, the concentration of FBZ in the second octanol phase was taken to be that of the original saline phase. A third extraction of the saline phase with fresh octanol verified that the second extraction was complete. All spectrophotometric measurements were conducted in octanol in which standard curves were determined and adherence to Beer's law verified. The same procedure was used for IBZ except that 10 to $25 \mu \mathrm{l}$ was pipetted initially and absorbance was measured at $228 \mathrm{~nm}$. The partition coefficients of $F B Z$ and $I B Z$ were each obtained at a minimum of two concentrations to establish that saturation of the saline phase had not occurred.

SYNTHESIS OF LABELED IODOBENZENE. Freshly distilled aniline $(200 \mu \mathrm{mol})$ in $2.0 \mathrm{ml}$ of $6 \mathrm{~N}$ hydrochloric acid was added to a $15 \mathrm{ml}$ round-bottom flask fitted with a septum seal. The solution was cooled to $-5^{\circ} \mathrm{C}$ under nitrogen, and $200 \mu \mathrm{mol}$ of sodium nitrite $(137.6 \mu \mathrm{l}$ of a $10 \%$ aqueous solution) was added. After 20 minutes of stirring, 100 $\mu \mathrm{mol}$ of sodium iodide in $200 \mu \mathrm{l}$ of water was added, followed immediately by 25 to $35 \mathrm{mCi}$ of $\left[{ }^{123} \mathrm{I}\right] \mathrm{Na}$ or 5 to 10 $\mathrm{mCi}$ of [125] $\mathrm{Na}$ in 0.1 to $0.3 \mathrm{ml}$ of $0.1 \mathrm{~N}$ sodium hydroxide. Two minutes later an additional $100 \mu \mathrm{mol}$ of sodium iodide in $200 \mu \mathrm{l}$ of water was added. The reaction was stirred at $0^{\circ} \mathrm{C}$ for 10 minutes, then at room temperature for 4 hours for synthesis of ${ }^{123}$ I-labeled IBZ or 20 hours for ${ }^{125}$ I-labeled IBZ. The reaction flask was cooled to $0^{\circ} \mathrm{C}$ and $10 \mathrm{mg}$ of unlabeled IBZ was added, followed by slow addition of approximately $1.5 \mathrm{ml}$ of $10 \mathrm{~N}$ sodium hydroxide to alkalinize the solution. Four milliliters of diethyl ether was added and the biphasic mixture was stirred vigorously at $0^{\circ} \mathrm{C}$ for 5 minutes. A few drops of $10 \%$ sodium thiosulfate solution were added and the contents of the flask were transferred to a separatory funnel. The aqueous layer was discarded and the ether layer washed consecutively with water $(3 \times 1 \mathrm{ml}), 6 \mathrm{~N}$ hydrochloric acid $(1 \times 1 \mathrm{ml})$, water $(2 \times 1 \mathrm{ml})$ and saturated saline solution $(1 \times 1 \mathrm{ml})$. The ether phase was transferred to a two-armed flask containing $0.96 \mathrm{ml}$ of absolute ethanol and $0.24 \mathrm{ml}$ of Polysorbate- 80 . The latter agent prevented IBZ from creeping up the sides of the flask. A mild stream of nitrogen was used to evaporate the ether slowly from the ethanol solution over a 1-hour period. The ethanol-Polysorbate-80 solution of ${ }^{123} \mathrm{IBZ}$ ( 5 to $8 \mathrm{mCi}$ yield) or ${ }^{125} \mathrm{IBZ}$ (2 to $5 \mathrm{mCi}$ yield) was stored at $0^{\circ} \mathrm{C}$ in the dark prior to use. For intravenous injection, 3 vol of sterile water were added slowly to the ethanol solution and stirred vigorously. A $10 \mathrm{ml}$ multidose vial with a Teflon-coated rubber septum was used for the formulation procedure.

CHROMATOGRAPHY. High-pressure liquid chromatography (HPLC) was performed on a Waters Model ALC/ GPC 204 Chromatograph with a $\mu$ Bondapak C-18 column $(3.9 \times 300 \mathrm{~mm})$. The radiochemical purity of ${ }^{125} \mathrm{IBZ}$ as determined by HPLC was routinely greater than $95 \%$ $\left(\mathrm{CH}_{3} \mathrm{OH} / \mathrm{H}_{2} \mathrm{O}: 80 / 20,1.0 \mathrm{ml} / \mathrm{min}, \mathrm{t}_{\mathrm{r}}=5.85 \mathrm{~min}\right)$. Radioactivity was quantified by counting 20-second effluent fractions in a Packard Model 5230 gamma counter.

AUTORADIOGRAPHY. Thirty seconds, 2 minutes, or 45 minutes following intravenous injection of a bolus of ${ }^{125} \mathrm{IBZ}(0.5$ to $1.0 \mathrm{mCi} / \mathrm{kg})$ in the ethanol-waterPolysorbate vehicle, animals were killed by rapid intravenous injection of sodium pentobarbital followed by decapitation. The brains were rapidly dissected from the skull and frozen in crushed dry ice. Coronal tissue sections $20 \mu \mathrm{m}$ thick were cut in a Harris Model WRC cryostat at $-20^{\circ} \mathrm{C}$. The frozen sections were picked up on prechilled $\left(-20^{\circ} \mathrm{C}\right)$ glass slides and placed on dry ice for temporary storage. Slides were subsequently exposed to Kodak SB-5 x-ray film at $-70^{\circ} \mathrm{C}$ for two to four days.

QUANTITATIVE TISSUE DISTRIBUTION. In quantitative tissue distribution experiments, awake, restrained rabbits were infused via the marginal ear vein with ${ }^{125} \mathrm{IBZ}(5$ to $15 \mu \mathrm{Ci} / \mathrm{kg}$ body weight $)$ at a constant rate $(0.05$ to $0.20 \mathrm{ml}$ $\mathrm{kg}^{-1} \mathrm{~min}^{-1}$ ) by means of a Harvard infusion pump. Timed arterial blood samples were obtained at 10 -minute intervals by percutaneous catheterization of the central ear artery contralateral to the infusion site. Blood was rapidly withdrawn in $1 \mathrm{ml}$ glass syringes and expelled onto a block of dry ice for subsequent analysis. Thirty seconds, 20 minutes, 40 minutes, or 60 minutes following initiation of the infusion, animals were killed by rapid intravenous administration of sodium pentobarbital followed by decapitation. Duplicate samples of cerebral cortex, caudate nucleus, cerebral peduncle, or optic nerve, each weighing 10 to 50 $\mathrm{mg}$, were dissected and frozen on dry ice. Subsequent to freezing, tissue and blood samples were weighed on an analytical balance and transferred to vials containing $1.5 \mathrm{ml}$ of distilled water for gamma counting as described previously. Raw data were expressed as counts per minute per gram of tissue or blood.

IN VIVO IMAGING. Three in vivo imaging procedures were performed on the monkey: (1) lateral and anteroposterior roentgenograms at close to $1: 1$ magnification; (2) a tomographic brain scan with [ ${ }^{99 \mathrm{~m}} \mathrm{Tc}$ ]pertechnetate; and (3) a tomographic brain scan using ${ }^{123} \mathrm{IBZ}$. The radiographs were obtained to provide skull dimensions and a frame of reference for the tomographic image planes. The monkey's head was placed in contact with the film cassette approximately 1 $m$ from the $x$-ray source. 
A pseudorandom time-coded aperture was used to obtain both sets of tomographic radioisotope images. The device and its imaging characteristics are fully described elsewhere [30]. The tomographic images obtained with this aperture were calculated using a modified version of the ART (an algebraic reconstruction technique) algorithm [14]. The images are longitudinal tomograms in the sense that the slices lie in planes parallel to the aperture. For the ${ }^{99 m}$ Tc scan, the aperture was used with an Ohio Nuclear Series 110 wide field-of-view camera, while an Ohio Nuclear 420 portable camera was used for the ${ }^{123} \mathrm{IBZ}$ scan. In each case the anesthetized monkey was placed in a stereotaxic frame and positioned such that the orbitomeatal line was perpendicular to the aperture, which was located 2 $\mathrm{cm}$ behind the monkey's head.

Before the ${ }^{99 m} T c$ scan was begun, five radioactive markers consisting of $5 \mathrm{~mm}$ diameter pieces of ${ }^{99 \mathrm{~m}^{\top} \mathrm{T}} \mathrm{T}$-labeled filter paper were affixed to the monkey's skull (see Fig 3). The markers were then imaged with the coded aperture in order to provide depth references for reconstruction of slices. Following this, the markers were removed and the monkey was injected with $10 \mathrm{mCi}$ of ${ }^{99 \mathrm{~m}} \mathrm{Tc}$ and imaged for 20 minutes. Conventional nontomographic images were also obtained.

In the case of the ${ }^{123} \mathrm{IBZ}$ scan, the arterial response curve to a constant-rate infusion of ${ }^{125} \mathrm{IBZ}$ in the monkey was first determined. Laplace transform techniques [22] were used to calculate the necessary injection schedule to yield a constant arterial concentration of tracer. A $1.52 \mathrm{mCi}$ bolus $(3.8 \mathrm{ml})$ of ${ }^{123} \mathrm{IBZ}$ was injected, followed by a constant infusion of $0.04 \mathrm{mCi}$ per minute $(0.1 \mathrm{ml} / \mathrm{min})$. Imaging began 30 minutes after the initial bolus, and the imaging time was divided into a 10 -minute period followed by a 5 -minute period in order to determine whether a steady-state concentration in the brain had been established. Marker scans and conventional views were obtained in an identical manner to that used for ${ }^{99 m} \mathbf{T} c$.

Virtually identical tomographic planes were reconstructed at approximately $1 \mathrm{~cm}$ intervals for the ${ }^{99 \mathrm{~m}} \mathrm{Tc}$ and ${ }^{123} \mathrm{IBZ}$ scans. In each case the images were scaled to the same size. In the plane that portrayed the markers in best focus, the marker centroid was flagged with a light pen and reference flags were added to the appropriate image planes.

\section{Results}

PARTITION COEFFICIENTS. Octanol to saline partition coefficients were determined as indices of rela- tive lipophilicity. The partition coefficients of the six substances presented in the Table are in general agreement with known published values [18, 21, 26]. The data are uncorrected for solute ionization.

AUTORADIOGRAPHY. To verify that IBZ is an appropriate agent for myelin imaging, the distribution of ${ }^{125} \mathrm{IBZ}$ was examined autoradiographically in the brains of three rabbits. Autoradiographs from the two sacrificed at 2 and 45 minutes following bolus injection of ${ }^{125} \mathrm{IBZ}$ demonstrated a pattern of retention of the label characteristic of histological myelin stains (Fig 1). In addition to brain white matter, pial blood vessels appeared to be heavily labeled. The distribution of ${ }^{125} \mathrm{IBZ}$ in the third rabbit, examined 30 seconds following injection of tracer (not shown), was heterogeneous (see Discussion).

QUANTITATIVE TISSUE DISTRIBUTION. Since the noninvasive methods employed subsequently require stable tissue concentrations of tracer during the imaging process, quantitation of ${ }^{125} \mathrm{IBZ}$ uptake by brain was examined using a more appropriate injection method. The time course of normalized arterial ${ }^{125}$ IBZ concentration during constant-rate infusion is shown in Figure 2. Arterial levels were essentially constant after 40 minutes, allowing at least $20 \mathrm{~min}$ utes for equilibration of brain tissue in the animals infused for 1 hour. The brain concentrations of ${ }^{125}$ IBZ (relative to blood) indicate that initial tissue uptake was greater in gray than in white matter, as shown by the optic nerve/cerebral cortex ratio (inset to Fig 2). With time, however, this pattern was reversed, and white matter became more heavily labeled than gray. Blood to brain equilibrium appeared to have been established after 40 minutes, since neither tissue uptake nor the optic nerve/cortex ratio increased between 40 and 60 minutes. Thus, the normalized tissue uptake values at 60 minutes are representative of the regional brain to blood partition coefficients for IBZ. Using optic nerve and cerebral cortex as representative tissues, the equilibrium white matter/gray matter ratio for IBZ is $1.8: 1$.

Octanol to Saline Partitioning and Equilibrium Distribution of Tracers in Brain

\begin{tabular}{llll}
\hline Tracer & Log $\mathrm{P}^{*}$ & White/Gray Ratio & Reference \\
\hline Antipyrene & $0.25 \pm 0.006$ & 1.0 & {$[29](\mathrm{rat})$} \\
Phenobarbital & $1.06 \pm 0.006$ & 1.1 & {$[11]$ (human) } \\
Iodoantipyrene & $1.18 \pm 0.009$ & 1.0 & {$[31](\mathrm{rat})$} \\
Fluorobenzene & $2.32 \pm 0.017$ & $\ldots$ & {$[11]$ (human) } \\
Diphenylhydantoin & $2.37 \pm 0.019$ & 1.4 & Present study (rabbit) \\
Iodobenzene & $3.29 \pm 0.023$ & 1.8 &
\end{tabular}

" $\log _{10}$ of the octanol to saline partition coefficient. Values are the mean \pm SEM of four determinations except for fluorobenzene, which had six determinations. 

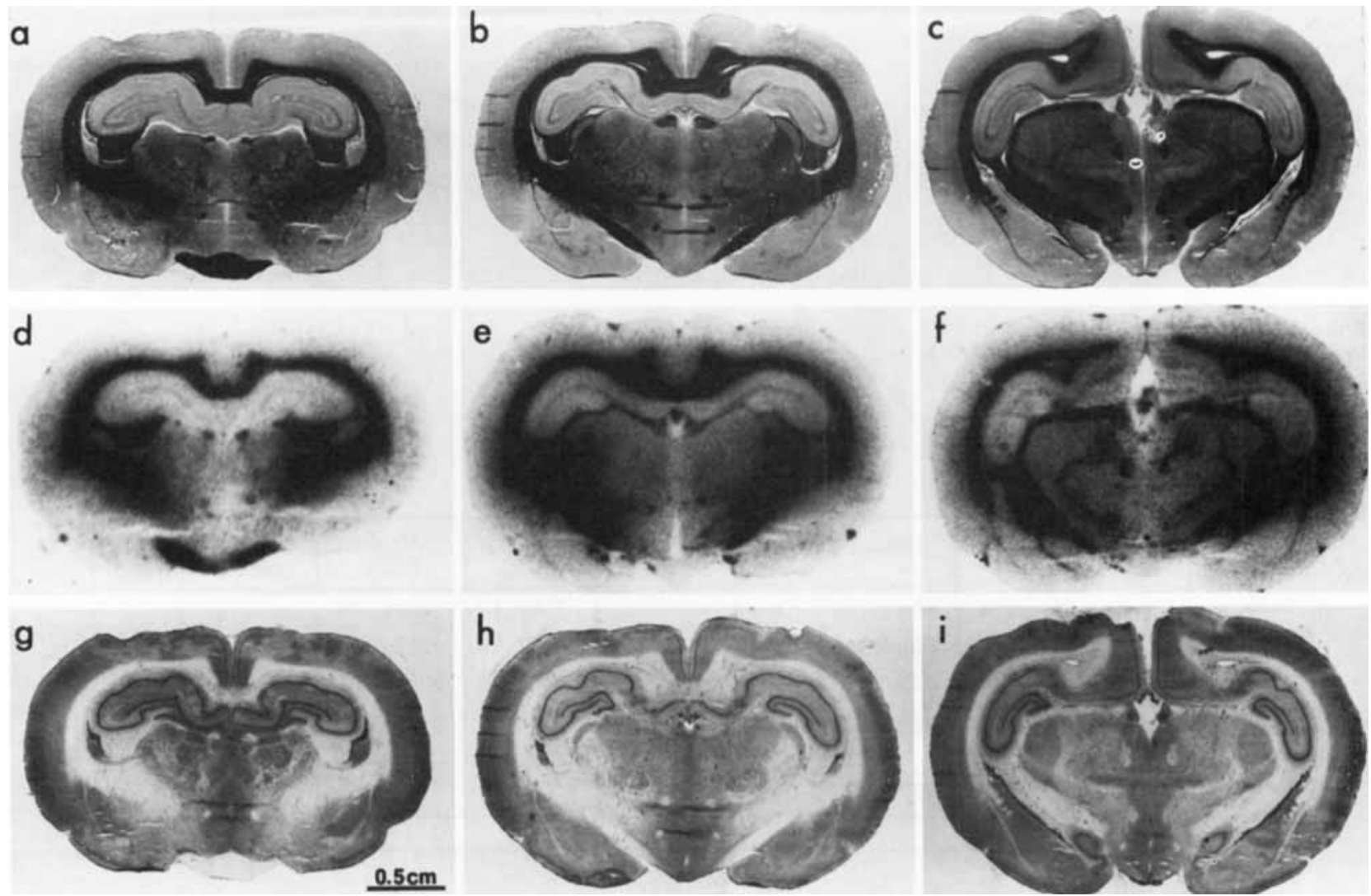

Fig 1. Autoradiograpbic distribution of ${ }^{125} I B Z$ in rabbit brain. Coronal sections through three brain regions (vertical rows) are compared. (a-c) Weil-stained sections of rabbit brain indicating myelinated structures. $(d-f)$ Autoradiograms showing the distribution of ${ }^{125} I B Z 45$ minutes following bolus intravenous injection. $(g-i)$ Nissl-stained brain sections indicating cellular regions (gray matter). The distribution of ${ }^{125} I B Z$ appears to reflect regional brain myelin content.

IN VIVO IMAGING. Results of the imaging procedures are shown in Figures 3 and 4. Locations of the ${ }^{99 \mathrm{~m}} \mathrm{Tc}$ markers are schematically represented on lateral and anteroposterior skull roentgenograms (Fig 3). The ${ }^{99 m}$ Tc scan (Fig 4a-c) demonstrates several characteristic features. The parotid and thyroid glands are heavily labeled by pertechnetate, while brain tissue demonstrates very low levels of activity since pertechnetate does not cross the intact bloodbrain barrier. In contrast, the 10 -minute ${ }^{123} \mathrm{IBZ}$ scan shows extensive uptake of tracer by brain tissue (Fig $4 \mathrm{~d}-\mathrm{f}$ ), which, within limitations of spatial resolution, corresponds to the distribution of white matter in monkey brain. The pattern of ${ }^{123} \mathrm{IBZ}$ uptake was both qualitatively and quantitatively similar in the 10-minute and 5-minute scans, suggesting that equilibrium had, in fact, been established.

\section{Discussion}

The purpose of the present study was to develop a radiographic technique for the differential visualization of brain white matter for eventual clinical application. While white matter can be distinguished from surrounding gray matter by low-energy transmission tomography, the effective contrast berween these tissues is severely limited by statistical noise [3], which may limit the effectiveness of the method when lesions selectively involve myelin structure or composition. Use of transmission tomography in detection of multiple sclerosis plaques, for example, results in a marginal correlation between scan abnormalities and clinically predicted lesions [28]. An emission technique that could selectively image white matter therefore appears to have potential clinical value.

In order to develop such a method, a number of requirements must be satisfied. Emission tomographic techniques generally require stable tracer concentrations in tissue throughout the scanning period in order to produce a meaningful reconstruction. Experimental approaches must take into account that the kinetics of blood to tissue transport of inert, diffusible substances are determined largely by the rate of tissue perfusion, while the equilibrium distributions of such tracers depend only on the regional tissue to blood partition coefficients [12]. The more 


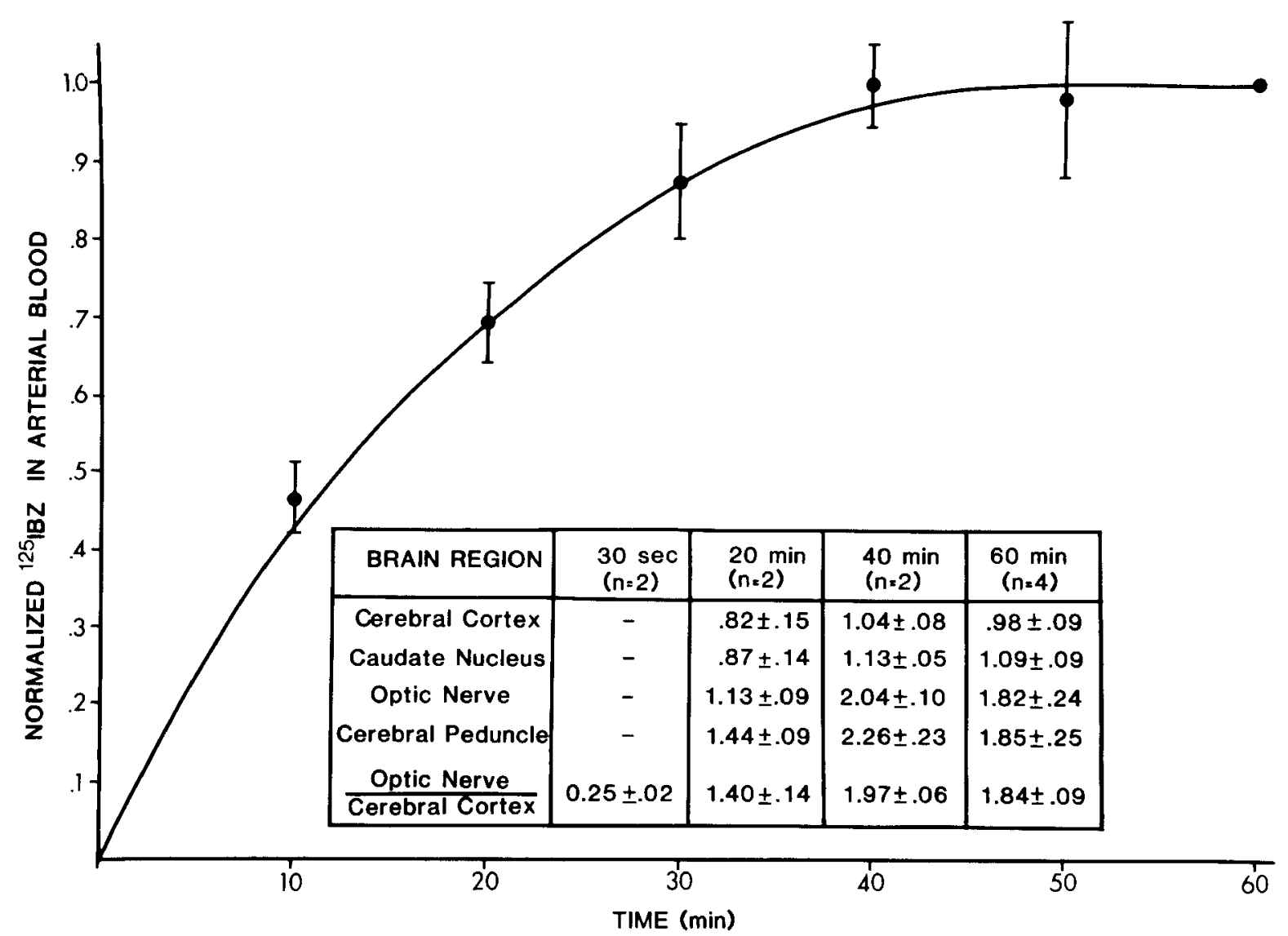

Fig 2. Time course of ${ }^{125} \mathrm{IBZ}$ concentration in arterial blood during constant-rate intravenous infusion in the rabbit. Data are normalized to blood concentrations at 60 minutes and represent the mean $\pm S E M$ for four animals. (Inset) Brain distribution of ${ }^{125} I B Z$ during constant-rate infusion. Data represent the mean $\pm S E M$ of the brain (cpm/mg) to blood (cpm/mg) ratio at the time of sacrifice in four brain regions. The bottom row shows the ratio of optic nerve to cerebral cortex uptake and is an index of the relative white to gray matter distribution. Only the optic nervelcortex ratio is shown at 30 seconds since accurate timing of blood measurements in these animals was metbodologically precluded.
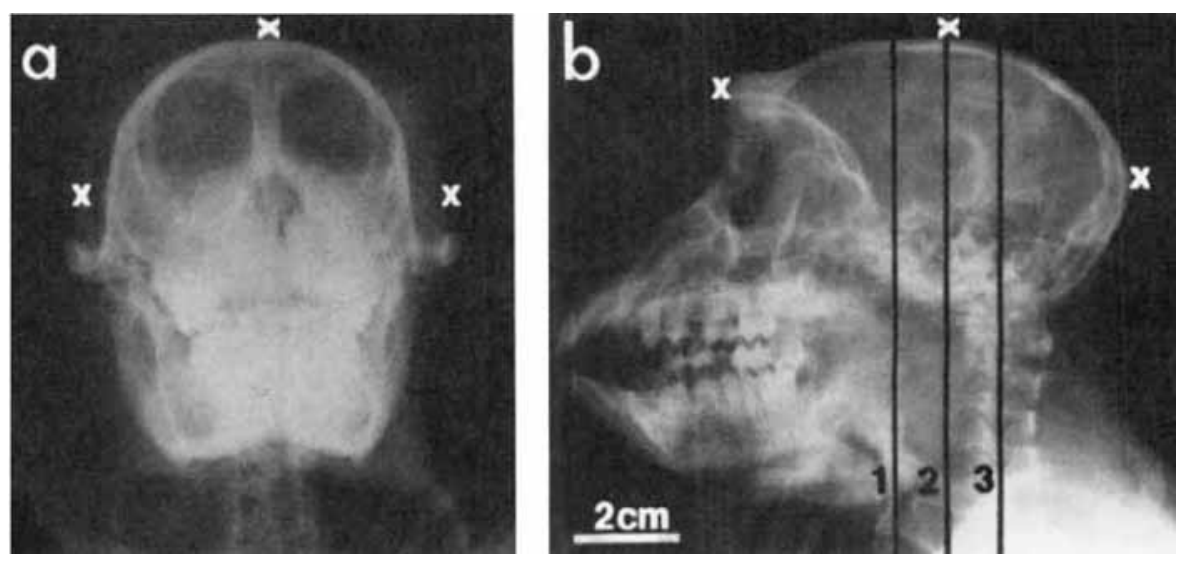

Fig 3. Roentgenographic views of the monkey used in the noninvasive imaging experiments. (a) Anteroposterior view. Locations of the ${ }^{99 \mathrm{~m}} T_{\mathrm{c}}$ reference markers (see text) in the midcoronal plane are indicated $(x)$. (b) Lateral view, showing lo- cations of markers in the midsagittal plane $(\mathrm{x})$ as well as planes of reconstruction $(1,2$, and 3 ) used in tomographic imaging procedures. 

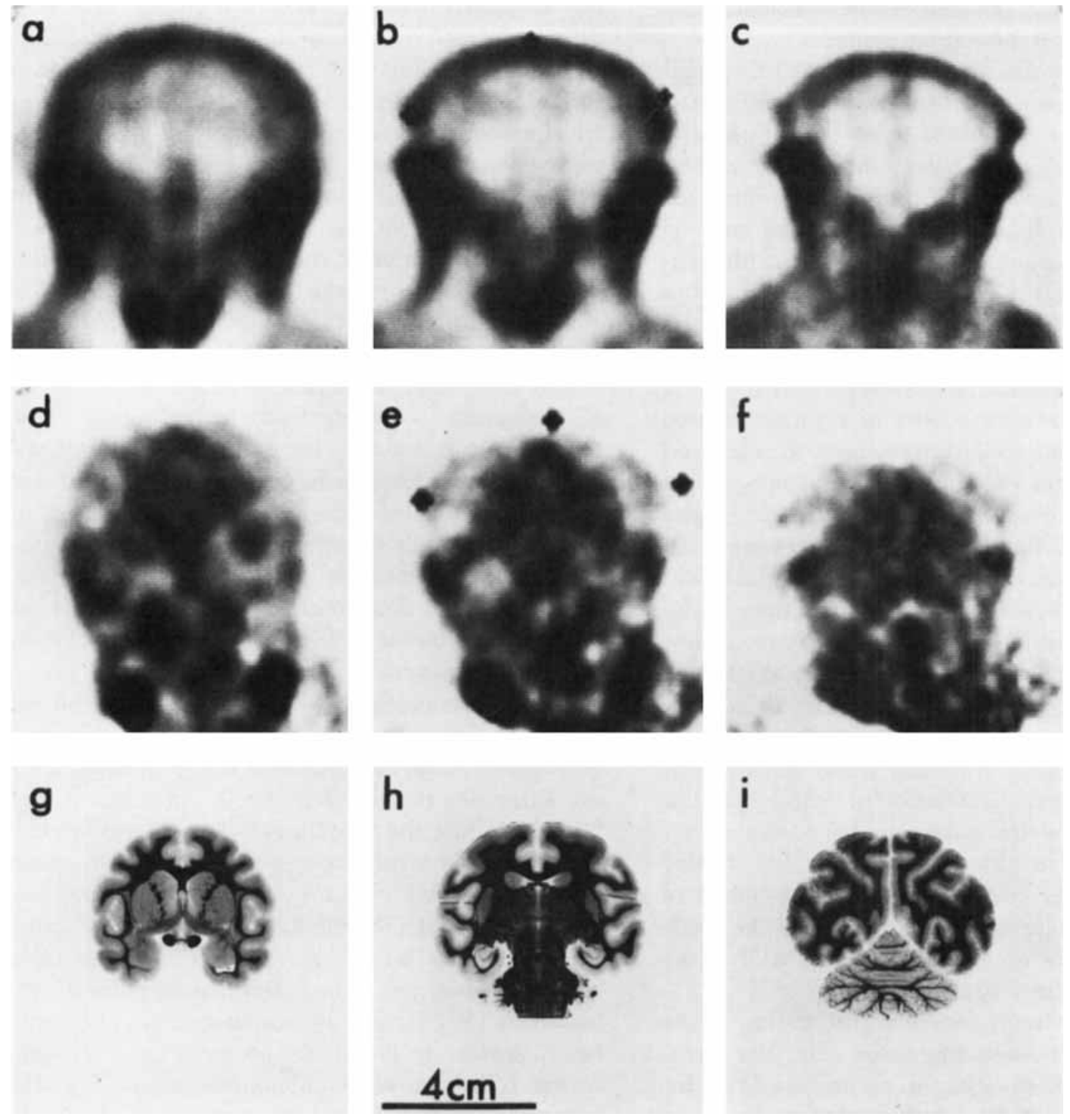

Fig 4. Noninvasive myelin scan of the monkey. (a-c) Coronal tomograpbic images of the bead (corresponding to planes $1-3$, respectively, in Fig 3) following administration of $\left[{ }^{99 m} T_{c}\right] p e r-$ technetate. (d-f) Coronal tomographic images during infusion of ${ }^{123} I B Z,(g-i)$ Osmium-stained sections of monkey brain demonstrating distribution of brain lipid. Darker areas in both ${ }^{99 m} T c$ and ${ }^{123} I B Z$ scans represent regions of increased uptake of tracer. Locations of markers (see Fig $3 a$ and Methods) are designated by plus signs (b and e). Note the degree of correlation between the ${ }^{123} I B Z$ scan (e) and the osmium staining (b) in the parietal lobes. Imaging is optimal in this region since the distribution of subcortical white matter does not change appreciably over the slice thickness $130 \mathrm{~J}$ of the coded aperture tomogram.

highly perfused gray matter should thus show faster saturation or desaturation than white matter following an increase or decrease in blood levels of tracer. While autoradiography following bolus intravenous injections of ${ }^{125} \mathrm{IBZ}$ demonstrates the feasibility of differential myelin labeling, this protocol does not provide the constant tissue concentrations of IBZ required for noninvasive imaging. In order to stabilize regional brain concentrations of tracer, arterial levels must remain constant long enough for establishment of tissue to blood equilibrium. This was accomplished in the present study after 40 minutes of constant-rate infusion of ${ }^{125} \mathrm{IBZ}$ in rabbits, or more rapidly by a bolus injection followed by a constantrate infusion of ${ }^{123} \mathrm{IBZ}$ in the monkey.

Since equilibrium distributions reflect the regional brain to blood partition coefficients of tracers, they may provide quantitative datá particularly useful for comparison studies, e.g., longitudinally in the same subject or between subjects. For improved contrast at the cost of quantitation, one could theoretically exceed the equilibrium ratio of white to gray matter labeling (between $2: 1$ and $3: 1$ ) by scanning during tracer washout from brain, under which conditions regional blood flow further enhances differential retention of tracer by white matter. This qualitative ap- 
proach may become feasible as the efficiency and time resolution of tomographic scanners improve.

Radiolabeled myelin imaging agents share several biochemical, physical, and practical requirements. They should cross the blood-brain barrier rapidly, distribute preferentially in brain white matter, and be metabolically inert. Clinically useful agents must additionally contain high-specific-activity gamma- or positron-emitting radionuclides and be readily synthesized and purified. Ideally, brain uptake of a myelin tracer should be limited only by cerebral blood flow, i.e., rapid equilibrium between capillary blood and tissue should be achieved. This property reduces the total radiation dose to a patient in two ways. First, the time needed to establish the required constant levels of tracer in brain prior to tomographic imaging is minimized. Second, the fraction of the systemically administered dose delivered to the brain is maximized, since this highly perfused organ will become saturated with tracer earlier than more poorly perfused regions such as adipose tissue. Thus, favorable dosimetry is offered by those agents for which accumulation in brain is least limited by blood-brain barrier permeability. Among tracers that satisfy this criterion, further selection of an optimal agent requires consideration of isotope half-life (positron emitters are attractive from this standpoint), solubility in blood (particularly for inhaled agents), and tracer metabolism. The dosimetry of ${ }^{123} \mathrm{IBZ}$ remains to be established, although the mode of degradation and excretion of IBZ as well as the chemical toxicity have been reported $[2,27]$.

The search for inert, rapidly equilibrating radiotracers has, in fact, been underway since the introduction of the Kety-Schmidt technique [13] for determining cerebral blood flow (for review, see [16]). Methods utilizing iodoantipyrene 131], trifluoroiodomethane $\left(\mathrm{CF}_{3} \mathrm{I}\right)$ [9], $n$-butanol [32], or butylphenylthiourea [10] all rely upon rapid equilibration of tracer across the blood-brain barrier to relate tissue uptake to the rate-limiting variable, cerebral blood flow. Several studies have demonstrated a correlation berween solute lipophilicity and permeability of the blood-brain barrier $[6,17,20,21,25]$. Rapoport et al [26] found that in the rat, $\log \mathrm{P}$ (the logarithm of the octanol to saline partition coefficient) of a tracer is predictive of the log of cerebral capillary permeability. From these experiments and other studies on brain extraction of tracers from blood [7, $8,19,31$, it may be concluded that putative myelin imaging agents, as well as blood flow imaging agents, must have $\log P$ values of 1.0 or greater to minimize blood-brain barrier limitations on tracer uptake. As is suggested in the following discussion, useful myelin imaging agents undoubtedly have even greater $\log \mathrm{P}$ values.

The present studies indicate that a desirable agent for imaging myelin by autoradiography may have different properties than one selected for clinical studies. Our results with the autoradiographic localization of ${ }^{125} \mathrm{IBZ}$ demonstrate that the tracer eventually localizes in brain white matter following bolus intravenous injection. We would anticipate that at very early times following injection, the tracer would be concentrated in gray matter. Autoradiograms of brain 30 seconds after injection, however, demonstrated a variable pattern of labeling suggestive of some artifactual redistribution of the label during tissue processing. This may be attributed either to diffusion of ${ }^{125} \mathrm{IBZ}$ through the tissue or to surface redistribution resulting from volatilization. Lowtemperature techniques for autoradiography of volatile substances have been described [5, 9], but they are tedious to perform and require specialized apparatus. Although volatile agents may prove advantageous in noninvasive imaging since pulmonary clearance from the circulation may effectively reduce the biological half-life of the tracer, they are not ideal for autoradiographic experiments.

The lipid content of white matter (based on wet weight of tissue) is between 2.5 and 3 times that of gray matter in the human brain $[1,23]$. Therefore it is not surprising that in early studies on regional cerebral blood flow, the lipophilic tracer $\mathrm{CF}_{3} \mathrm{I}$ was found to concentrate in myelin at equilibrium [9]. This property complicated blood flow calculation since regional corrections for the local tissue to blood partitioning of $\mathrm{CF}_{3} \mathrm{I}$ were required. A number of other known substances, including thiopentone [4], halothane [5, 17], and diphenylhydantoin [11], have been shown to distribute preferentially in white matter following systemic administration. The data presented in the Table demonstrate a correlation between tracer lipophilicity and the observed equilibrium distribution ratio between white and gray matter. While antipyrene, phenobarbital, and iodoantipyrene $(\log \mathrm{P}=0.25,1.06$, and 1.18 , respectively) cross the blood-brain barrier readily, they distribute uniformly throughout the brain at equilibrium $[11,29,31]$. The more lipophilic diphenylhydantoin $(\log \mathrm{P}=2.37)$ demonstrates preferential accumulation in white matter [11], although the observed white-to-gray matter distribution ratio of 1.4:1 would suggest that both diphenylhydantoin and the potential positron-emitting molecule FBZ $(\log \mathrm{P}=2.32)$ would be only marginally useful in noninvasive imaging situations. The white to gray distribution ratio $(1.8: 1)$ observed in this study for IBZ $(\log \mathrm{P}=3.29)$ is similar to that found by Freygang and Sokoloff [9] for $\mathrm{CF}_{3} \mathrm{I}$ ( $\log \mathrm{P}$ unknown), suggesting that these agents might be equally suitable for use in a clinical myelin imaging technique.

The highest observed ratio of white to gray matter accumulation for any of the agents thus far studied is 
approximately $2: 1$, while the theoretical maximum ratio based on lipid content is expected to be closer to $3: 1$. Although agents with $\log \mathbf{P}$ values greater than IBZ may prove to have distribution ratios approaching $3: 1$, it is also possible that the observed tissue distributions result from more complex properties of myelin than its total lipid content. For example, the distributions might reflect the lipid/ protein ratio, specific membrane components, or other factors. The apolar lipid cholesterol, for instance, may have higher affinity for lipophilic agents than the highly polar inositol phosphatides. The development of agents that bind to molecules enriched in myelin, such as cerebroside, cerebroside sulfate, or the myelin proteins (e.g., proteolipid protein, myelin basic protein), may lead to even greater imaging contrast between gray and white matter and between normal myelin and pathologically altered myelin. The present results, using a single-photonemitter in the monkey, give promise that both single-photon imaging and the rapidly developing technology of positron-emission tomography will be successfully applied to imaging of myelinated structures in the human brain.

Supported by Grant NS 15655 from the National Institutes of Health. K. A. F. is a trainee of NIH Grant 1 T32 GM07863.

Presented in part at the Seventh Meeting of the International Society for Neurochemistry, Jerusalem, Israel, September, 1979, and at the Ninth Annual Meeting of the Society for Neuroscience, Atlanta, GA, November, 1979.

The authors thank Dr M. Nahrwold, Department of Anesthesiology, for useful discussions, and acknowledge with thanks the use of the facilities of the Phoenix Memorial Laboratory of the University of Michigan.

\section{References}

1. Brante G: Studies on lipids in the nervous system with special reference to quantitative chemical determinations and topical distribution. Acta Physiol Scand 18 [Suppl 63]:13-189, 1949

2. Brodie BB, Reid WD, Cho AK, et al: Possible mechanism of liver necrosis caused by aromatic organic compounds. Proc Natl Acad Sci USA 68:160-164, 1971

3. Brooks RA, Di Chiro G, Keller MR: Explanation of cerebral white-gray contrast in computed tomography. J Comput Assist Tomogr 4:489-491, 1980

4. Cassano GB, Ghetti B, Gliozzi E, Hansson E: Autoradiographic distribution study of "short acting" and "long acting" barbiturates: ${ }^{35} \mathrm{~S}$-thiopentone and ${ }^{14} \mathrm{C}$-phenobarbitone. $\mathrm{Br} \mathrm{J}$ Anaesth 39:11-20, 1967

5. Cohen EN, Chow KL, Mathers L: Autoradiographic distribution of volatile anesthetics within the brain. Anesthesiology 37:324-331, 1972

6. Crone $C$ : The permeability of brain capillaries to nonelectrolytes. Acta Physiol Scand 64:407-417, 1965

7. Eckman WW, Phair RD, Fenstermacher JD, et al: Permeability limitation in estimation of local brain blood flow with [14C]antipyrine. Am J Physiol 229:215-221, 1975

8. Eklof B, Lassen NA, Nilsson L. et al: Regional cerebral blood
How in the rat measured by the tissue sampling technique; a critical evaluation using four indicators $C^{14}$-antipyrine, $C^{14}$ ethanol $\mathrm{H}^{3}$-water and xenon ${ }^{133}$. Acta Physiol Scand 91:1-10, 1974

9. Freygang $\mathrm{WH} \mathrm{Jr}_{\mathrm{J}}$, Sokoloff L: Quantitative measurement of regional circulation in the central nervous system by the use of radioactive inert gas. Adv Biol Med Phys 6:263-279, 1958

10. Goldman SS: A new family of unsymmetrical thiourea derivatives to measure cerebral blood flow. In Passonneau JV, Hawkins RA, Lust WD, Welsh FA (eds): Cerebral Metabolism and Neural Function. Baltimore, Williams \& Wilkins, 1980

11. Harvey CD, Sherwin AL, Van Der Kleijn E: Distribution of anticonvulsant drugs in gray and white matter of human brain. Can J Neurol Sci 4:89-92, 1977

12. Kety SS: The theory and applications of the exchange of inert gas at the lungs and tissues. Pharmacol Rev 3:1-41, 1951

13. Kety SS, Schmidt CF: The nitrous oxide method for the quantitative determination of cerebral blood flow in man: theory, procedure and normal values. J Clin Invest 27:476483,1948

14. Koral KF, Rogers WL: Application of ART to time-coded emission tomography. Phys Med Biol 24:879-884, 1979

15. Kuhl DE, Edwards RO, Ricci AR, Yacob RJ, Mich TJ, Alavi A: The Mark IV system for radionuclide computed tomography of the brain. Radiology 121:405-413, 1976

16. Lacombe P, Meric P, Seylaz J: Validity of cerebral blood flow measurements obtained with quantitative tracer techniques. Brain Res Rev 2:105-169, 1980.

17. Larson CP Jr, Eger EI II, Severinghaus JW: The solubility of halothane in blood and tissue homogenates. Anesthesiology 23:349-355, 1962

18. Leo A, Hansch C, Elkins D: Partition coefficients and their uses. Chem Rev 71:525-616, 1971

19. Ohno K, Pettigrew KD, Rapoport SI: Local cerebral blood flow in the conscious rat as measured with ${ }^{14} \mathrm{C}$-antipyrine, ${ }^{14} \mathrm{C}$-iodoantipyrine and ${ }^{3} \mathrm{H}$-nicotine. Stroke 10:62-67, 1979

20. Oldendorf WH: Lipid solubility and drug penetration of the blood brain barrier. Proc Soc Exp Biol Med 147:813-816, 1974

21. Oldendorf WH: The blood-brain barrier. Exp Eye Res (suppl): 177-190, 1977

22. Patlak CS, Pettigrew KD: A method to obtain infusion schedules for prescribed blood concentration time courses. J Appl Physiol 40:458-463, 1976

23. Radin NS, Akahori Y: Fatty acids of human brain cerebrosides. J Lipid Res 2:335-341, 1961

24. Raichle ME: Quantitative in vivo autoradiography with positron emission tomography. Brain Res Rev 1:47-68, 1979

25. Raichle ME, Eichling JO, Straatmann MG, et al: Blood-brain barrier permeability of ${ }^{11} \mathrm{C}$-labeled alcohois and ${ }^{15} \mathrm{O}$-labeled water. Am J Physiol 230:543-552, 1976

26. Rapoport SI, Ohno K, Pettigrew KD: Drug entry into the brain. Brain Res 172:354-359, 1979

27. Reid WD, Krishna G, Gillette JR, Brodie BB: Biochemical mechanism of hepatic necrosis induced by aromatic hydrocarbons. Pharmacology 10:193-214, 1973

28. Reisner T, Maida E: Computerized tomography in multiple sclerosis. Arch Neurol 37:475-477, 1980

29. Reivich M, Jehle J, Sokoloff L, Kety SS: Measurement of regional cerebral blood flow with antipyrine- ${ }^{14} \mathrm{C}$ in awake cats. J Appl Physiol 27:296-300, 1969

30. Rogers WL, Koral KF, Mayans R, et al: Coded aperture imaging of the heart. J Nucl Med 21:371-378, 1980

31. Sakurada $O$, Kennedy C, Jehle J, et al: Measurement of local cerebral blood flow with iodo $\left[{ }^{14} \mathrm{C}\right]$ antipyrine. Am J Physiol 234:H59-H66, 1978

32. Van Uitert RL, Levy DE: Regional brain blood flow in the conscious gerbil. Stroke 9:67-72, 1978 